\title{
EL QUIEBRE EN LA AUTOPISTA EDUCATIVA: ¿UN CURRÍCULUM PARA SEGUIR SIN PARAR O PARA CAMBIAR DE RUMBO?
}

\section{THE CRACK IN THE EDUCATIONAL HIGHWAY: A CURRICULUM TO KEEP GOING NON-STOP OR TO CHANGE COURSE?}

\author{
Sebastián Guerrero Lacoste \\ Magíster (c) en Educación mención currículum y comunidad educativa \\ Universidad de Chile \\ sebastianguerrero@ug.uchile.cl \\ Constanza Cárdenas Alarcón \\ Magíster en Educación mención currículum y comunidad educativa \\ Universidad de Chile \\ constanzacardenas@ug.uchile.cl
}

\begin{abstract}
Resumen: La irrupción del COVID-19 obligó a los países de Latinoamérica y el Caribe a generar múltiples respuestas educativas para dar continuidad a los programas de estudios establecidos. Sin embargo, más allá de las políticas gubernamentales y las propuestas de los organismos internacionales para enfrentar la crisis, han emergido ideas, experiencias $\mathrm{y}$ proyectos que han tomado en consideración el contexto que han vivido las y los estudiantes al interior de las propias escuelas y comunidades educativas. En este documento utilizamos la metáfora del viaje para comentar algunos elementos en torno al trabajo de los profesores y profesoras en el contexto de la pandemia, focalizándonos en particular en una experiencia de trabajo colaborativo y construcción curricular participativa que tuvo lugar en una escuela particular subvencionada de la región metropolitana de Santiago, considerando además las condiciones estructurales del sistema educativo chileno que han sido determinantes para hacer de este viaje, un viaje mucho más complejo.
\end{abstract}

Palabras clave: curriculum, trabajo docente, construcción curricular, pandemia.

Resumo: 0 surgimento do COVID-19 obrigou os países da América Latina e do Caribe a gerar múltiplas respostas educacionais para dar continuidade aos programas de estudos estabelecidos. Porém, para além das políticas governamentais e das propostas de organismos internacionais para enfrentar a crise, surgiram ideias, experiências e projetos que têm levado em conta o contexto que os alunos têm vivido nas suas próprias escolas e comunidades. Neste documento, utilizamos a metáfora da viagem para comentar alguns elementos em torno do trabalho dos professores no contexto da pandemia, focalizando em particular uma experiência de trabalho colaborativo e de construção curricular 
participativa ocorrida em uma escola privada subsidiada no. região metropolitana de Santiago, considerando também as condições estruturais do sistema educacional chileno que foram decisivas para tornar esta viagem muito mais complexa.

Palavras chave: currículo, trabalho docente, construção de currículo, pandemia.

Abstract: The outbreak of COVID-19 forced Latin American and Caribbean countries to generate multiple educational responses to provide continuity to established curricula. However, beyond government policies and proposals from international organizations to face the crisis, ideas, experiences, and projects have emerged that have taken into consideration the context experienced by students within schools and educational communities. In this document, we use the metaphor of the journey to comment on some elements regarding the work of teachers in the context of the pandemic, focusing in particular on an experience of collaborative work and participatory curriculum construction that took place in a private subsidized school in the metropolitan region of Santiago, also considering the structural conditions of the Chilean education system that have been decisive in making this journey a much more complex one.

Key words: curriculum, teacher's work, curriculum construction, pandemic.

\section{LA ESCUELA CHILENA EL 2020 EN LA AUTOPISTA DEL SUR}

La obra de Lakoff y Johnson (1986) representa quizás, unos de los aportes más importantes al hablar de las metáforas en el uso cotidiano. Lejos de configurar una realidad extraordinaria, las metáforas penetran tanto en el lenguaje como en nuestro pensamiento y acción. En ese sentido, pareciera ser un recurso especialmente interesante a la hora de describir una experiencia vivida en cuanto "la esencia de la metáfora es entender y experimentar un tipo de cosa en términos de otra” (Lakoff y Johnson, 1986, p. 41).

Desde ahí, que la popular metáfora "el tiempo es espacio" pareciera poder ayudarnos a explicitar una característica fundamental de las vivencias humanas vinculadas a su componente histórico, siendo ampliamente utilizada en muchas culturas y lenguas, la cual podría ayudarnos a re-visitar la experiencia de la pandemia, en particular lo sucedido en el mundo educacional con énfasis en el currículum, campo donde la metáfora ya ha ocupado un terreno importante (Grundy, 1998; Ross, 2000).

El viaje, como símbolo de experimentar el tiempo de manera física dialoga con la famosa historia del argentino Julio Cortazar (1964) Autopista del Sur, cuento que relata un embotellamiento de autos en la entrada de la ciudad de París, en donde personas desconocidas se organizan para sobrellevar el atochamiento, en la espera de que las autoridades logren descongestionar la autopista de entrada a la ciudad en condiciones especialmente complejas. En ese espacio de paso rápido y aislado de la autopista, se viven experiencias constitutivas de lo humano como la muerte, el amor, el compañerismo y el cuidado mutuo para resolver necesidades, así como el desgaste permanente de las personas 
en la eterna espera. Sin embargo, cuando la crisis pasa, pareciera ser que esas experiencias se difuminan, iniciando nuevamente la carrera y el apuro por llegar primero.

Dialogando con la metáfora del viaje y el cuento de Cortázar, levantaremos, por lo tanto, la idea del viaje que experimentó la escuela chilena durante el año 2020 para organizar este texto, año en que se detuvo la carga prescriptiva del currículum técnico y se abrieron espacios de posibilidad para un currículum práctico y un currículum crítico (Grundy, 1998). Desde la óptica de la experiencia del profesorado presentaremos una experiencia de construcción curricular participativa que se desplegaron de manera colectiva en el marco de la crisis del Covid-19, y por ende del cierre de las escuelas, en el contexto de las escasas respuestas de las autoridades chilenas por generar apoyos consistentes y pertinentes a la realidad de las comunidades escolares.

\section{PUNTO DE PARTIDA: EL CHOQUE DEL COVID-19}

"A nadie le cabía duda de que algún accidente muy grave debía haberse producido en la zona, única explicación de una lentitud tan increíble. Y con eso el gobierno, el calor, los impuestos, la vialidad, un tópico tras otro, tres metros, otro lugar común, cinco metros, una frase sentenciosa o una maldición contenida."

Iniciando el año 2020, Chile se encontraba en un proceso de Revuelta Popular iniciada el 18 de octubre de 2019 por el movimiento estudiantil secundario al que se sumaron amplios sectores populares y que se mantuvo durante los meses siguientes. Este período de agitación se expresó en movilizaciones a nivel nacional, agitación en diversos territorios y en la emergencia de instancias de deliberación comunitaria y popular a través de cabildos y asambleas territoriales, teniendo por efecto a nivel estatal, la posibilidad de plebiscitar y cambiar la constitución política de la dictadura (Cabezas y Guerrero, 2021). En este contexto, tras la masiva marcha del 8 de marzo en conmemoración del día de la mujer que convocó a dos millones de ellas, el lunes 16 del mismo mes el gobierno decide suspender las clases presenciales del sistema educativo producto de la crisis sanitaria que imponía la reciente llegada del COVID 19 a Chile.

Desde un principio, la respuesta del gobierno de Chile a la pandemia no fue precisamente acertada. Tomás Perez-Acle (2020), biólogo computacional que integró la Mesa de datos Covid 19 impulsada por el Estado, señaló en una entrevista a finales de marzo que "si hubiéramos tomado las medidas hace tres semanas, no estaríamos lamentando esta situación. El colapso del sistema sanitario hoy es inevitable". Desde marzo de 2020 a la fecha no han sido pocos los signos de un mal manejo de la pandemia por parte del gobierno incluyendo la falta de transparencia en datos de personas contagiadas y fallecidas (El Mostrador, 2020), medidas antojadizas y autoritarias (Agüero, 2021; Bacigulpe, 2021), inexistencia de trabajo en la Mesa Asesora Covid-19 (Colmed, 2021; Vera, 2021), y ausencia de una estrategia institucional coordinada para hacer frente a la pandemia (Siches, 2020; Pierola, 2020; Cienfuegos et al., 2020; Gutierrez, 2020). 
En este marco, la respuesta del Ministerio de Educación (desde ahora señalado como Mineduc) no ha estado exenta de tensiones y polémicas. Ante el shock inicial de la pandemia y la suspensión de las clases presenciales, el Mineduc se lanzó en una cruzada solitaria instalando el lema de "aprender sin parar" que se expresó en dos importantes esfuerzos: intentar mantener todos los elementos posibles del funcionamiento pre-pandémico del sistema escolar, y forzar la vuelta a clases presenciales independiente de las condiciones sanitarias del momento.

En relación al esfuerzo de mantener "la normalidad" del sistema escolar podemos destacar dos elementos problemáticos. El primero relacionado a la obsesión por la cobertura curricular de los objetivos de aprendizaje, sobre todo al inicio del confinamiento, sostenida en el tiempo, lo cual fue resuelto por las autoridades mediante una "poda curricular" (Caro, 2018a) derivando en la propuesta de priorización curricular del Ministerio de Educación. Es decir, para que se pudiera desarrollar la cobertura curricular, se jibariza la prescripción del currículum. Mientras, en su antípoda, el Colegio de Profesoras y Profesores de Chile presentó una propuesta de "nuclearización curricular" que apostaba por la generación de procesos educativos integrados y contextualizados en las realidades de las comunidades educativas (Colegio de profesoras y profesores, 2020; Cárdenas et al., 2021).

El segundo aspecto problemático se relaciona con las lógicas de evaluación y rendición de cuentas instaladas en el sistema escolar. En mayo de 2020, sin haber elaborado un plan o estrategia para el resguardo de las comunidades educativas (Foro por el Derecho a la Educación Pública, 2020), en plena alza de contagios con más de 30 mil casos acumulados y 1400 casos diarios (Ministerio de Salud, 2020), el ministro de educación señaló que a fin de año se aplicaría la prueba del SIMCE, decisión ampliamente rechazada por múltiples actores educativos e investigadores, la cual finalmente, fue suspendida por una iniciativa parlamentaria (Sisto, 2020; Cornejo y González, 2020a).

Respecto al retorno presencial a clases, el Mineduc, en vez de optar por una estrategia que generara las condiciones sanitarias para volver a clases presenciales a mediano y largo plazo, o apoyar la realización de clases online, pareciera que se orientó a generar las condiciones legales para la presencialidad reduciendo las exigencias para volver a la normalidad. Si hasta octubre de 2020 el retorno a clases presenciales era obligatorio en fase 4 (Mineduc, 2020), en febrero sería en fase 2 (Minsal, 2021), y en julio de 2021 en fase 1 (Gobierno de Chile, 2021).

En relación a la respuesta del Mineduc debemos señalar entonces que, en la misma línea del gobierno, durante el período de la pandemia el Ministerio no ha generado una estrategia articuladora para coordinar el trabajo de los distintos actores involucrados en el funcionamiento del sistema escolar (Díaz, 2021; Cornejo y González, 2020b), ni siquiera ha generado apoyos significativos para los establecimientos y las comunidades educativas (Sisto, 2020; Red Estrado y OPECH, 2020). Junto con Sisto (2020) consideramos que la escuela fue abandonada y dejada a su suerte por el Ministerio y sus políticas de rendición de cuentas, pues, lamentablemente, aún en el año 2021 es vigente lo señalado por Mario Sobarzo (2020, p. 67): 
"lo ocurrido durante 2020 no fue educación a distancia o tele-educación, sino una respuesta sobre la marcha con grandes problemas estructurales, escasa preparación previa de las y los docentes, incapacidad de apoyo desde los organismos centrales o directamente desconocimiento de la realidad escolar"

Si desde las instancias centrales no se han generado las condiciones materiales o sanitarias para una vuelta presencial, ni propuestas o apoyos significativos para la educación en línea, y se han querido sostener a ultranza los dispositivos de rendición de cuentas como la cobertura curricular, SIMCE, y evaluación docente, junto con Sisto (2020) y Sobarzo (2020) es posible sostener que la educación chilena en este periodo ha debido ser el profesorado y las comunidades educativas quienes sacando adelante los procesos escolares durante el año 2020 y 2021.

\section{LAS CONDICIONES DEL ATOCHAMIENTO}

"El calor de agosto se sumaba a ese tiempo a ras de neumáticos para que la inmovilidad fuese cada vez más enervante. Todo era olor a gasolina, gritos destemplados de los jovencitos del Simca, brillo del sol rebotando en los cristales y en los bordes cromados, y para colmo sensación contradictoria del encierro en plena selva de máquinas pensadas para

Un punto clave puesto en la discusión pública tiene relación con la existencia o no de las condiciones para un eventual retorno a clases. Este ha sido, sin duda, el nudo central de las discordancias entre el Ministerio (Figueroa, 2021) y magisterio Colegio de profesoras y profesoras, 2021), e incluso las municipalidades (La Tercera, 2021). Si miramos un poco hacia atrás, desde una perspectiva histórica, y recordamos el caso emblemático del liceo acuático que detonó la Revolución Pingüina de 2006 (Ramírez y Comunicaciones CIAE, 2016), la invitación de un Ministro de educación a los colegios a hacer bingos para mejorar sus condiciones de infraestructura (El Mostrador, 2018), o las dos décadas de movilizaciones contra la educación de mercado (Foro por el Derecho a la Educación Pública, 2015; Caro y Reyes, 2020), resuena con actualidad la sentencia de la ACES (2011) de que el sistema de educación pública en Chile ha sido arrasado por un verdadero terremoto neoliberal. Es decir, las condiciones del sistema educativo ya eran precarias previo a la pandemia, cuyos efectos se han profundizado. Si aceptamos por un momento esta afirmación, creemos importante lograr abordar someramente un abordaje histórico para comprender el problema de fondo. ¿En qué condiciones se encontraba la autopista antes del choque? ¿Cómo estaba construida? ¿Cómo era la relación entre los actores que transitaban a diario en ella? ¿Qué tiene que ver el neoliberalismo con las condiciones del sistema educativo? ¿Qué relación tiene el neoliberalismo con los efectos devastadores del Coronavirus en el sistema educativo?

El origen del COVID 19 no ha dejado de ser afirmado y negado por diferentes versiones, creando tantas historias que finalmente ha terminado por perder su relevancia para la opinión pública, cuyo abordaje no pasó de ser superficial, conspiranoico o farandulero. Sería interesante saber si ha sido abordado de forma profunda y sistemática en el conjunto del sistema educativo. 
Desde un primer acercamiento podríamos comprender que este virus surge en el mundo. No uno abstracto sino un mundo que en los últimos siglos ha sido condicionado progresivamente por el sistema capitalista y en las últimas décadas, por su fase neoliberal. Esto es relevante porque la relación que establece este sistema con la naturaleza está orientada únicamente a la acumulación de riqueza, lo cual se traduce en la depredación de ecosistemas y en la producción intensiva del agronegocio con peligrosas consecuencias como el calentamiento global o, en este caso, la proliferación de las condiciones para la emergencia y la propagación de virus hipercompetitivos. (Colectivo Chuang, 2020; Harvey, 2020; De Sousa, 2020)

Sin ánimos de extendernos en esto, existen variados autores que señalan que el Covid 19, lejos de ser un virus "aparecido de la nada", es parte de las consecuencias de la explotación que el capital ejerce contra la naturaleza, así como la gripe aviar, la porcina, o el calentamiento global. Por otro lado, los motivos por los cuales este virus se pudo expandir e impactar tan gravemente a nivel global corresponde a la primacía del capital por sobre la vida, razón por la cual no se pudo impedir la propagación internacional del virus por intereses económicos, y que las reformas neoliberales han producido la degradación de derechos sociales privatizados (De Sousa, 2020, Harvey, 2020; Chuang, 2020; Badiou, 2020).

Esta situación es particularmente importante para el caso de Chile, debido a que fuimos el primer experimento del neoliberalismo instalado durante la dictadura de Pinochet (Harvey, 2007), el cual fue profundizado durante los gobiernos de la transición a la democracia (Grez y Foro por la Asamblea Consituyente, 2015; Ruiz, 2010). La economía y la sociedad chilena sigue siendo profundamente neoliberal. Es paradójico el caso de la educación, donde las transformaciones de los gobiernos de la transición a la democracia no se enfocaron en volver a democratizar o garantizar el derecho a la educación, sino que crearon nuevas reformas neoliberales de privatización y lógicas de mercado en la educación (Caro y Reyes, 2020; Ruiz, 2010).

Para una comprensión general del sistema educativo neoliberal, Miguel Caro y Leonora Reyes (2020) han señalado que dentro del marco de la constitución neoliberal de 1980 impuesta en dictadura y de la reestructuración implementada en los gobiernos de la post-dictadura, el sistema educacional se ha desarrollado en función de cuatro pilares fundamentales. Uno jurídico, relacionado al encuadre que brindaba la LOCE en la constitución de 1980 y más tarde la LGE de 2009; otro administrativo, referido al sistema de sostenedores, la ley de Aseguramiento de la Calidad de 2011 y los Servicios Locales de Educación en 2017; el pilar del financiamiento mediante la subvención a la demanda vía voucher; $y$, por último, el curricular, asociado al control de los contenidos educativos a través de la evaluación estandarizada del SIMCE.

A esto vale agregar la conceptualización ampliamente utilizada por actores educativos e investigadores académicos, que entiende a este modelo como una educación de mercado por regirse bajo lógicas mercantiles que incluyen: traspaso de fondos públicos a actores privados (Cornejo, 2018); disfrazar la libertad de mercado y lucro como libertad de enseñanza (González, 2015), su orientación hacia la formación de mano de obra para la economía neoliberal (Ruiz, 2010; ACES, 2011); generar procesos de privatización exógena y 
endógena (Caro y Reyes, 2020; Sisto, 2020); y fomentar la competencia entre los establecimientos para acceder a financiamiento (Assaél et al., 2015).

Se hace importante entonces, reconocer algunas de las consecuencias del proyecto educativo neoliberal ya que entendemos que las problemáticas generadas por la pandemia se entroncan y son más nocivas por las condiciones previas del sistema educacional de mercado. Efectos como el aumento de la segregación social (Sobarzo, 2020; ACES, 2011; OCDE, 2004; Gentili, 2001), la privatización de la educación en detrimento de lo público (Cornejo, 2018; Ruiz, 2010), una educación para formar trabajadores asalariados de la economía capitalista (Caro y Reyes, 2020; Ruiz, 2010), la vulneración de los derechos de actores de las comunidades educativas (Foro por el derecho a la educación pública, 2019), magros resultados en pruebas estandarizadas (Sisto, 2020; Ruiz, 2010), una educación autoritaria y poco participativa, la pérdida del sentido de la educación (Assaél et al, 2015), y una experiencia educativa conservadora, de tipo colonial y patriarcal que sitúa "la experiencia formativa en una clave adaptativa y reproductora de la estratificación sociolaboral, de la construcción valórica hegemónica y de la subjetividad dominante" (Caro y Reyes, 2020, p. 18). En ese sentido, la irrupción del Covid 19 sumó elementos y profundizó el desastre producido por el terremoto neoliberal en el sistema educativo en Chile.

Por otro lado, en el ámbito curricular las problemáticas previas a este período de excepcionalidad no han sido pocas. A pesar de que este no ha sido un eje central de las demandas de los movimientos por la educación, ha habido expresiones de ello siendo ampliamente discutidas a nivel académico. Dentro de dichos asuntos destacan la democratización y descentralización curricular (Cárdenas et al, 2021; ACES, 2011; Magendzo, 2008; Pinto, 2005), el contenidismo, la fragmentación curricular y la parcelación de la realidad (Caro y Aguilar, 2018), la racionalidad técnico-instrumental de los documentos curriculares (Osandón y Pinto, 2018), la saturación de objetivos del currículum prescrito (Caro, 2018b) y el inflexible control estatal de los contenidos (Caro y Reyes, 2020).

Incluso desde las propias instancias centrales del sistema educativo se han reafirmado algunos de estos cuestionamientos dando paso a una posible transformación importante en el ámbito curricular. Así, por ejemplo, la Unidad de Currículum y Evaluación del Mineduc señaló en 2016 que:

“es posible identificar que el Currículum actual presenta dos grandes desafíos que complejizan su implementación: el primero dice relación con la extensión de la prescripción curricular, y el segundo, con la dificultad para su contextualización, impactada por la diversidad de categorías curriculares, que pueden implicar el riesgo de tender a una visión fragmentada del aprendizaje" (UCE-Mineduc, 2016, p.14 en Assaél, Albornóz y Caro, 2018, p.86)

En cuanto a las consecuencias de las políticas educativas en Chile, en el documento Bases administrativas, técnicas y anexos para la licitación del concurso de proyectos de reinserción educativa y aulas de reingreso, el Mineduc, a través de la División de Educación General, es categórico al señalar que: 
"La escuela no ha conseguido generar estrategias adecuadas para que los estudiantes con distinto capital cultural puedan integrarse al sistema escolar, reconociendo y validando su propia cultura, por el contrario, los segrega y estigmatiza, viéndolos como sujetos carentes de capacidades y disposiciones para aprender". (Mineduc, 2021, p.24)

Vale destacar que, incluso ante este tipo de conclusiones internas y en medio de la crisis del COVID-19, desde el Ministerio se ha intentado seguir abogando por las lógicas de la cobertura curricular (Departamento de educación y perfeccionamiento del Colegio de profesoras y profesores, s/f). Sin embargo, la pandemia trajo consigo un quiebre, una suerte de vacío de la prescripción curricular que el ministerio no pudo resolver hasta mediados de mayo, cuando el Consejo Nacional de Educación aprobó la propuesta de Priorización Curricular del MINEDUC (CNED, 2020). Incluso esta propuesta no significó una reposición del currículum oficial en todo el sistema escolar debido a su carácter de propuesta, a la indefinición acerca del tema de las calificaciones y a la imposibilidad de supervisión. En fin, las condiciones impuestas por la pandemia, ante un sistema escolar precarizado y la ausencia de un plan de respuesta alternativo para una situación como esta, interrumpieron el control curricular de los contenidos de aprendizaje del estado lo cual sin duda trajo consigo un desafío complejo y al mismo tiempo, una posibilidad de hacer las cosas de otra manera.

\section{LA ORGANIZACIÓN COLECTIVA}

"Cuando la niña volvió a quejarse de sed, al ingeniero se le ocurrió ir a hablar con los campesinos del Ariane, seguro de que en ese auto había cantidad de provisiones. Para su sorpresa los campesinos se mostraron muy amables; comprendían que en una situación semejante era necesario ayudarse, y pensaban que si alguien se encargaba de dirigir el grupo (la mujer hacía un gesto circular con la mano, abarcando la docena de autos que los rodeaba) no se pasarían apreturas hasta llegar a París"

En medio del caos, nacen varias experiencias colectivas para afrontar la pandemia y llenar "el vacío" y abandono en que queda la escuela en este periodo (Sisto, 2020). El trabajo colectivo que emerge entre los propios docentes al interior de los espacios cotidianos de las escuelas, que se trasladaron forzadamente a las pantallas logra en algunos casos, convertirse en una propuesta curricular, mirando el currículum no sólo como la prescripción de lo que se debe ejecutar, sino también creándolo, mediante el diálogo y la deliberación colectiva.

A continuación, comentaremos las principales características de la experiencia de construcción curricular participativa que hemos documentado parcialmente en un trabajo previo de Cárdenas y colaboradores (2021), y que hace eco con otras experiencias que han tenido algunos profesores y profesoras, que han utilizado las redes sociales, conversatorios y webinars para visibilizar proyectos de trabajo colectivo que buscan trascender las lógicas bancarias (Freire, 1970a). 
La experiencia de construcción curricular participativa que comentaremos tiene lugar en una comunidad escolar de la comuna de Peñalolén en Santiago de Chile, específicamente en el primer ciclo de enseñanza que considera los cursos de pre-kinder a tercero básico. En la experiencia participaron 16 profesoras, profesores y asistentes de la educación. Las actividades se desarrollaron principalmente de manera asincrónica mediante la plataforma virtual Facebook y tenían dentro de sus principios la nuclearización de los objetivos curriculares de aprendizaje, la organización del currículum a partir de temas generadores, el reconocimiento de los docentes y trabajadores de la educación como agentes legítimos de construcción curricular, y el trabajo multigrado y la diversificación de actividades de aprendizaje (Cárdenas et. al, 2021).

En la sección que viene a continuación describiremos los dos primeros, enfatizando los cambios a nivel de organización y diseño que tuvieron lugar en la propuesta curricular que se llevó a cabo el año 2020 y que orientarán la reflexión en el apartado final.

\section{NUCLEARIZACIÓN CURRICULAR}

En contraposición a la priorización curricular sugerida por el Ministerio de Educación Chileno, la nuclearización nace como propuesta desde el Colegio de Profesores y Profesoras de Chile para abordar la situación de excepcionalidad de la pandemia. En términos generales, la priorización propuesta buscaba posicionarse como una alternativa al enfoque cuantitativo asociado a la "poda de objetivos" y a los requerimientos de la cobertura curricular. En ese sentido, la nuclearización busca sintetizar y situar los aprendizajes desde una perspectiva integral, a partir del abordaje e interpretación de temáticas asociadas al contexto nacional o de las comunidades educativas (Colegio de Profesoras y Profesores de Chile, 2020).

En el caso de nuestro trabajo de nuclearización, se realizó basándose, entre otras cosas, en la propuesta que apunta a la reelaboración e integración de aprendizajes (Colegio de Profesoras y Profesores de Chile, 2020), sintetizando los objetivos de aprendizaje explicitados en el currículum pre-escrito, categorizando algunos elementos en torno a saberes relevantes, y unificándolos con otros de igual o distinto nivel. Lo anterior, se realizó bajo una perspectiva no-lineal del aprendizaje, atendiendo las diferencias personales del estudiantado, sobre todo, respecto a habilidades clave del inicio de la escolaridad como es la lectura y la escritura. Así mismo, se consideraron objetivos y temas que eran pertinentes de tratar dado el contexto en que se trabajaba, centrando el foco en la comunidad y el cuidado mutuo, énfasis resaltado también por otras comunidades y docentes a lo largo del país (Saberes Docentes, 2020).

A continuación, en la Figura 1, se observan los núcleos elaborados a partir de la reflexión colectiva de profesores y profesoras de 5 cursos distintos, las cuales de manera conjunta analizaron los objetivos de aprendizaje del nivel correspondiente en el marco de la diversidad de sus estudiantes, su contexto educativo concreto y las observaciones y comunicación sostenida con las madres y padres en este periodo. 


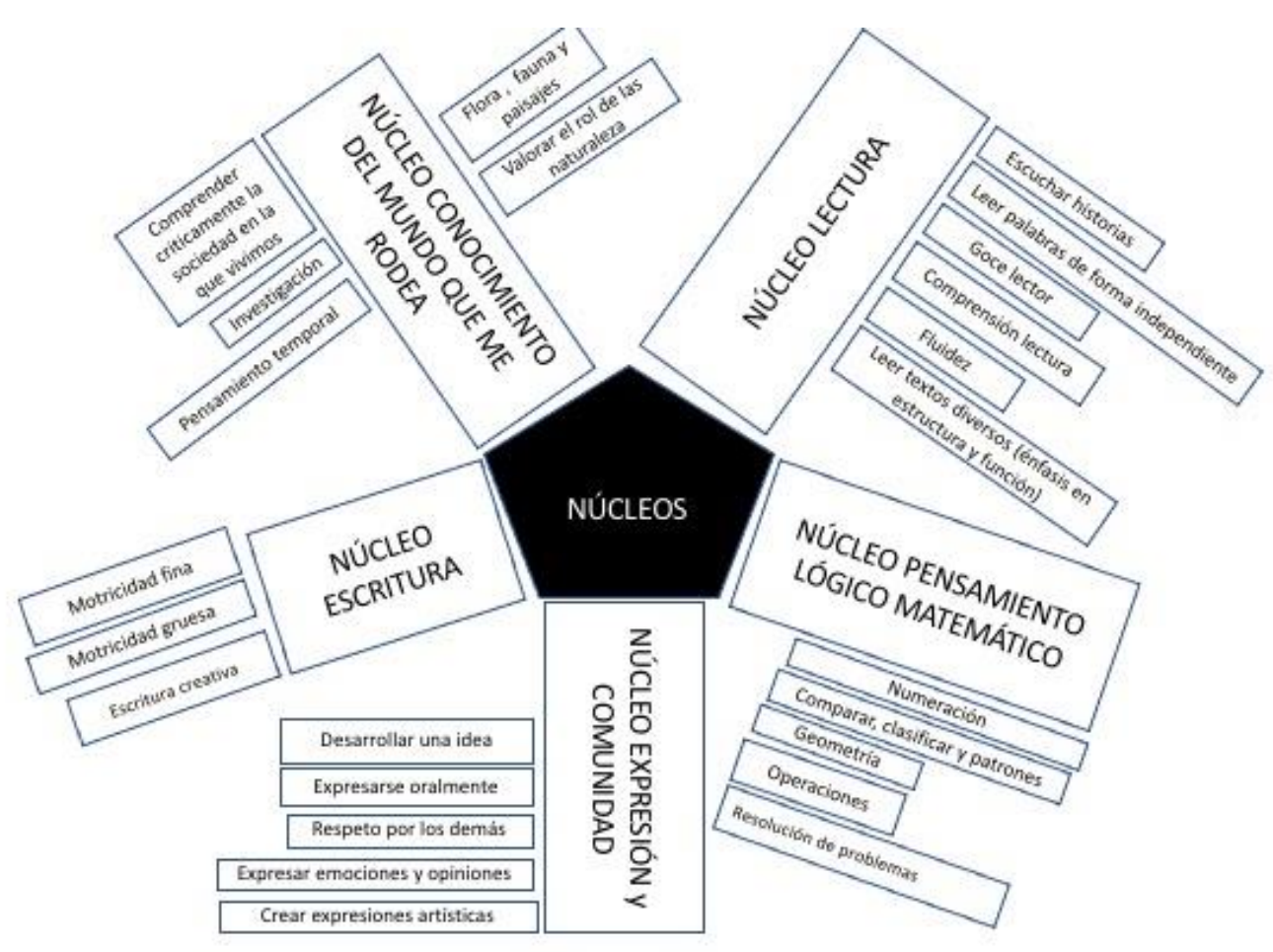

153

Figura 1. La Flor de la nuclearización. Los pétalos principales de la figura muestran los núcleos basados en la sintetización de ejes y objetivos de aprendizaje explicitados en el currículum nacional desde la educación parvularia a tercero básico. Fuente: elaboración propia.

Como se observa en la Figura 1, los núcleos de trabajo construidos por los docentes se constituyen por conceptos globales, lo suficientemente amplios como para ser abordados desde los distintos niveles, permitiendo así su flexibilización y diversificación a la hora de planificar experiencias de aprendizaje. Así mismo, estos núcleos a nivel organizacional no se encuentran sólo dentro de una asignatura y más bien aspiran a ser elementos que pueden ser combinados en una misma experiencia, dejando atrás la segmentación disciplinar por la que se rige el currículum pre-escrito (Assaél, et al., 2018; Caro y Aguilar, 2018).

Como se observa, se nuclearizaron con bastante énfasis, las áreas de lectura y escritura dada la creciente preocupación por el proceso de aprendizaje de estos temas por parte de los niños, niñas, apoderados y apoderadas de la comunidad. Lo anterior, constituyó complejas preguntas para el profesorado que los desafiaban, por una parte, a promover el desarrollo de la lectura y la escritura en niños y niñas que recién iniciaban el proceso en los niveles de educación parvularia y primero básico, y por otra, fomentar su desarrollo en muchos estudiantes que se encontraban en cursos superiores a estos y aún no lograban estos aprendizajes.

Por otro lado, la propuesta de nuclearización busca ser una carta de ruta para focalizar los esfuerzos en ciertos conceptos más enmarcados en el "contenido" en el marco de temas relevantes que promovieran aprendizajes más allá de lo establecido en los mismos núcleos. Es decir, si bien, la nuclearización propuesta logró reducir y esquematizar en alguna medida el programa de estudio de varias asignaturas de los niveles señalados en una propuesta 
propia, no restringió la emergencia de temas transversales, valiosos y relevantes para las realidades de los niños y niñas.

\section{TRABAJO CONTEXTUALIZADO BASADOS EN TEMAS GENERADORES}

En consideración a lo anterior, la propuesta curricular no residió exclusivamente en los núcleos de aprendizaje señalados, sino que se articuló en base a temas generadores que se desarrollaban al menos, durante 5 semanas.

La propuesta de temas generadores se inspira en los planteamientos de Freire como propuesta para orientar los procesos de post-alfabetización donde el conocimiento se perfila hacia la transformación de una realidad problemática. Desde la claridad de que una educación liberadora no puede ser una donación, ni menos una imposición que se hace al pueblo, sino que esta debe emerger y construirse con y para este, el pedagogo brasileño propone desarrollar una investigación temática donde, junto al pueblo, se investigue su realidad identificando los temas y problemas de las comunidades y la comprensión que se tiene sobre estos. Tras levantar y elaborar estos temas se puede comenzar a organizar el contenido programático de la educación, reduciendo o decodificando cada tema en sus aristas o sus núcleos centrales, para luego volver a codificarlos seleccionando la mejor forma de comunicar y presentar el tema a ser conocido (Freire, 1970a; 1970b).

Llevar a cabo un proceso de tal magnitud se encontraba fuera de las condiciones que teníamos en el desarrollo de esta experiencia. Aún así, encontramos inspiración en esta propuesta y la fuimos construyendo según nuestras propias posibilidades. En nuestro caso, los temas generadores tenían como objetivo, por un lado, ser un medio para transversalizar los distintos núcleos construidos, y por otro, convertirse en un puente que permitiera abordar problemáticas comunitarias, haciendo más explícito el vínculo entre el conocimiento y la realidad, la escuela y la sociedad. De igual forma, nos permitió escuchar los intereses de los niños y niñas en este periodo, logrando en algún punto de la experiencia, recoger las temáticas que emergían desde sus propios intereses.

Cabe señalar que este tipo de organización curricular presenta ciertas similitudes con las llamadas "metodologías por proyectos" o "Aprendizajes basados en problemas" que tienen como característica principal un tema o pregunta articuladora de las experiencias de aprendizajes. Un ejemplo de aquello en este tiempo de pandemia son algunas de las experiencias que profesores y profesoras han trabajado a lo largo del periodo de confinamiento y que han permitido que en varios niveles de enseñanza las asignaturas puedan estar articuladas por un tema central, promoviendo la contextualización, el aprendizaje situado y el involucramiento por parte de los estudiantes y sus familias (Equipos educativos de la Corporación Municipal de Renca, 2020).

Para facilitar la comprensión del proceso, a continuación, presentamos un ejemplo de tema generador, su organización y su uso para las planificaciones de las experiencias de aprendizajes propuestas por los equipos de trabajo. 


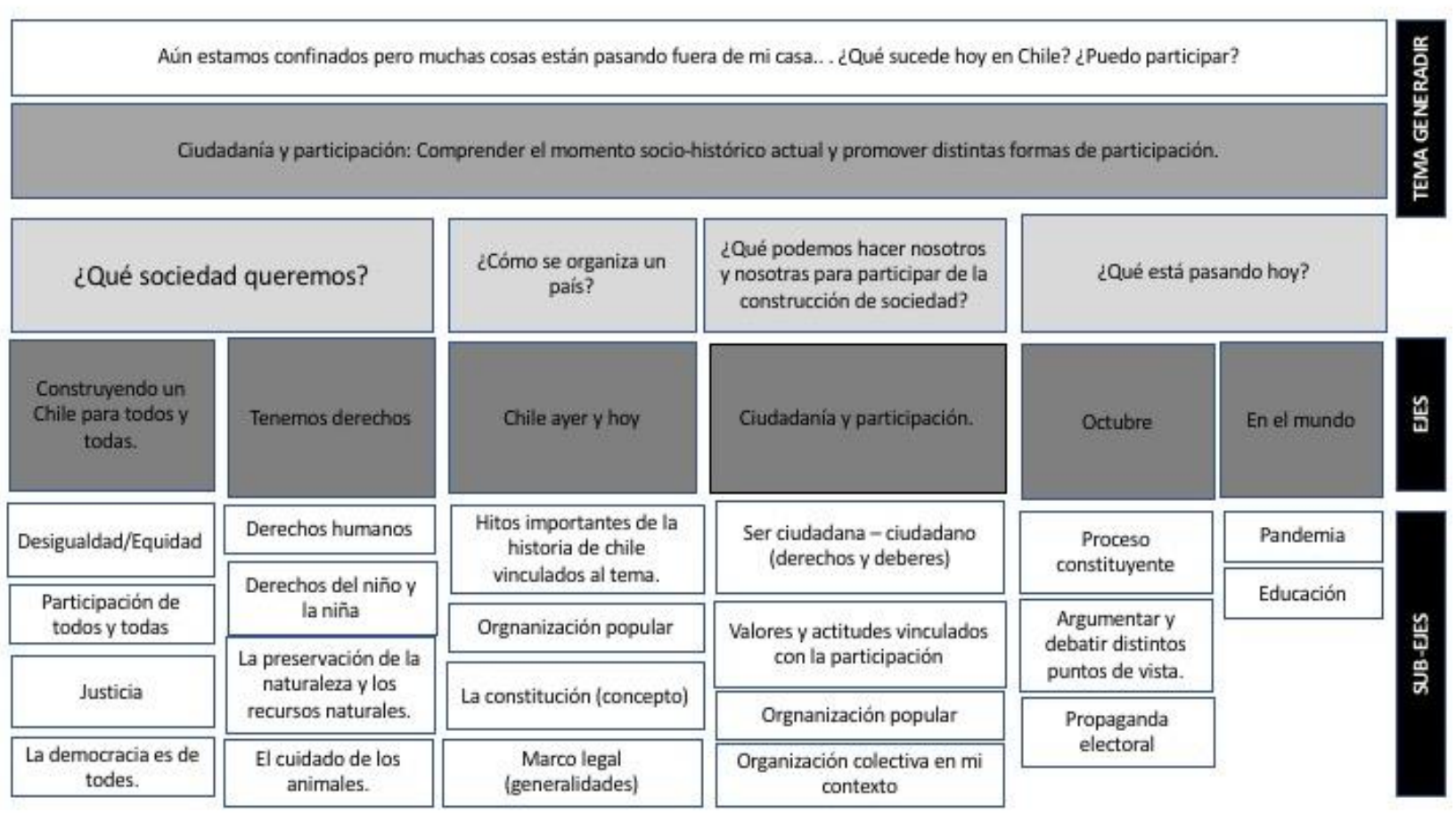

Figura 2. Esquema tema generador, ejes y sub-ejes. Fuente: elaboración propia

Como se puede observar, el tema generador está decodificado en varios ejes y subejes. Así mismo cada uno de estos niveles está precedido por preguntas resultantes de la reflexión acerca del tema generador conversado entre los distintos actores que componen el equipo de trabajadores y trabajadores de la educación.

En este caso, a partir de las distintas reflexiones y diálogos colectivos a propósito del histórico plebiscito realizado el 25 de octubre del año 2020, a un año del inicio de la revuelta del 18 de octubre del año anterior, nace un tema generador que no sólo se refiere al plebiscito en sí mismo, si no a conceptos como democracia, participación, el estado, formas de organización, entre otros temas. Para los y las trabajadores de la educación, este tema parecía ser fundamental dado el contexto que se estaba viviendo y permitía hacer partícipes a los niños y niñas de lo que diariamente escuchaban en la televisión y veían en sus barrios.

A partir de aquello, emergen varios ejes y sub-ejes posibles de trabajar en las experiencias de aprendizaje pudiendo ser utilizados de manera única o combinada entre ellos. Por ejemplo, la actividad puede centrarse en el sub-eje de justicia y al mismo tiempo, conectarse con el sub-eje de organización popular. Esto es fundamental, si se entiende que el tema generador posee múltiples aristas para ser abordado y por otra parte, que no es posible asumir que todos los niños y niñas presentan los mismos intereses y habilidades, y por lo tanto, era necesario fomentar el desarrollo de múltiples formas y/o caminos para su abordaje y comprensión. 
Ambos elementos, la nuclearización por una parte y la emergencia del tema generador por otra, facilitaron en gran medida, la posibilidad de generar actividades multigrado pues tanto los núcleos como los ejes y sub-ejes permiten flexibilidad de formas y niveles de logro generando involucramiento por parte de los estudiantes desde una perspectiva situada y contextualizada. Lo anterior, fue fundamental en el tiempo de pandemia, levantando no sólo una organización sólida del aspecto curricular socializado con las madres, padres y apoderados; si no al mismo tiempo, comprometiendo de manera más activa a los niños y niñas, incrementando de manera importante su participación en la plataforma.

\section{REFLEXIONES FINALES}

"sin que ya se supiera bien por qué tanto apuro, por qué esa carrera en la noche entre autos desconocidos donde nadie sabía nada de los otros, donde todo el mundo miraba fijamente hacia adelante, exclusivamente hacia adelante"

Sin duda el viaje de la pandemia y de la situación del COVID ha sido muy compleja en particular, para la educación chilena, la cual hace ya un tiempo venía agonizando producto de un sistema fuertemente mercantilizado. A partir de los elementos planteados en el apartado inicial, nos parece importante señalar que el atochamiento causado por el COVID19 y el cierre de las escuelas se vivió de una manera mucho más cruda en un sistema educativo que se encontraba en crisis previo a la pandemia. El clima de incertidumbre dificultó aún más el escenario, convirtiéndose en un tiempo angustiante y agotador, sobre todo para los profesores y profesoras. En ese sentido, el esfuerzo constante de los docentes para generar respuestas que atendieran al estudiantado y la sensación de inestabilidad ante las decisiones que se tomaban por parte la autoridad, en un contexto de apoyos tecnológicos insuficientes y escasa formación pedagógica para la educación online, trajo consigo sobrecarga laboral, malestar emocional y agotamiento (Red Estrado y OPECH, 2020) precarizando aún más un gremio frecuentemente culpabilizado y sobre-responsabilizado de los fracasos escolares de los y las estudiantes (Cornejo y Reyes, 2008).

Por otro lado, el llamado de aprender sin parar por parte de la autoridad promovió una visión mecanicista de la educación, olvidando el componente afectivo y relacional que la pedagogía considera (Sisto, 2020), centrando el foco de la escuela en la imposición de continuar la escuela en el hogar desde las ópticas bancarias. Sobre la respuesta del sistema escolar mexicano, Plá (2020) señala: "su actuación ha sido imponer la escuela en casa, antes de preguntarse cómo ofrecer apoyo en esta crisis sanitaria a la población que atiende" (p.32), situación que bien podríamos extrapolar al contexto chileno. Es decir, la deshumanización en este periodo ha estado fuertemente marcada por la lógica de economicista en la escolaridad, la que sin duda afecta y tensiona el quehacer del profesorado y sus oportunidades de transformar lo que se vive en la escuela, pero que, sin embargo, abre posibilidades para repensar cuestiones naturalizadas en el sistema escolar. Sobre esto Díaz-Barriga (2000) plantearía que "estamos ante un hecho inédito: la pérdida del espacio escolar y del aula" (p.20), situación que plantea nuevos desafíos, como la conjunción del trabajo, la escuela y la casa, instituciones que la modernidad había logrado separar (Puiggros, 2020). 
Desde la posibilidad que brinda el espacio-tiempo de la crisis de la pandemia y de la flexibilización del control curricular, algunas comunidades fueron capaces de organizarse y construir un currículum distinto a partir de la reflexión colectiva del sentido que tiene educar en estos tiempos, como se describió en esta experiencia. Así, el currículum prescrito deja de convertirse en una realidad estática inquebrantable, abriendo posibilidades a buscar otras opciones en su organización como la nuclearización curricular o el trabajo con temas generadores. Nos parece que, más allá de la excepcionalidad pandémica, esta propuesta curricular podría contribuir con ideas, principios o experiencias a proyectarse en el futuro para el desarrollo de una educación integral, democrática y vinculada a las realidades de las comunidades educativas. A su vez, esto hace necesario desarrollar metodologías para la producción de conocimiento pedagógico o curricular, dentro de lo cual la documentación curricular podría ser un aporte (Kridel, 2010).

Por otro lado, asumiendo los desafíos sociales e históricos del momento presente, es fundamental avanzar hacia la búsqueda de otras formas de hacer currículum o bien, de vivir el currículum. Para esto es necesario superar la barrera impuesta por el control de los contenidos que privilegia una lógica contenidista y estandarizada de la experiencia escolar (Caro y Reyes, 2020). Este constituye un elemento base para la discusión sobre la democratización del currículum y de la educación para comenzar a desplazarnos hacia otras formas de sociedad donde se ponga por centro la vida y la dignidad.

Si consideramos que la educación debe tener relación con las realidades de las personas, las comunidades y de la sociedad, podemos entender la pandemia y sus efectos devastadores como un grito de alerta para detenernos, sopesar el fenómeno y comprender sus causas fundantes. No solo para entenderlas, sino para prevenir y transformar las causas que originan semejante tragedia. Desde esta concepción, hemos identificado el modelo neoliberal como uno de los grandes problemas para las comunidades educativas, tanto por el origen de diversas pandemias como por los efectos de precarización de derechos sociales como la educación en Chile. De forma contradictoria, hemos visto que la fuerte carga de la prescripción curricular impide el desarrollo de una educación integral democrática y vinculada a las realidades de las comunidades educativas, la cual pudimos ensayar por el quiebre de esta prescripción en la experiencia relatada.

Nos preguntamos entonces, si el desenlace del cuento de la autopista educativa relatada en este documento se asemejará al cuento original de Cortázar ¿volveremos a la carrera en llegar la ciudad de las luces que nos encandilan con la estandarización, la competencia, el mérito y el éxito? 0 ¿será este quiebre educativo un momento para reflexionar y pensar en un currículum desde abajo, con sentido para las comunidades siendo sus mayores constructores los profesores y profesoras?

Ante las reflexiones emergidas de esta experiencia, y situándonos ante un eventual cambio del marco normativo que sostiene los pilares del modelo educativo neoliberal, incluyendo el control curricular, nos parece importante preguntarnos ¿Cuál es el rol que debieran tener las escuelas dentro de la sociedad y de sus territorios? ¿Cuál es el rol que debieran tener las comunidades educativas en la toma de decisiones de su propia educación? ¿Cuáles son las condiciones previas para construir currículum desde la participación 
deliberativa de las comunidades? ¿Qué esfuerzos serían necesarios para problematizar el sentido común que asocia la educación con el autoritarismo, el asignaturismo y lo bancario? ¿Cuál sería el sujeto o los sujetos de la educación postneoliberal? ¿Cómo es el proyecto de sociedad que queremos construir? 


\section{REFERENCIAS BIBLIOGRÁFICAS}

Asamblea Coordinadora de Estudiantes Secundarios (ACES) (2011). Propuesta para la educación que queremos. Quimantú.

Agüero, F. (21 de febrero de 2021) Felipe Agüero por medidas de seguridad en la pandemia: "Le van dando mayor poder al Ejecutivo en materia de control" https://radio.uchile.cl/2021/02/21/felipe-aguero-por-medidas-de-seguridad-en-lapandemia-le-van-dando-mayor-poder-al-ejecutivo-en-materia-de-control/

Assaél, J., Cornejo, R., Albornoz, N., Etcheberrigaray, G., Hidalgo, F., Ligueño, S., y Palacios, D. (2015) La crisis del modelo educativo mercantil chileno: un complejo escenario". Currículo sem Fronteiras, 15(2), 334-345.

Assaél, J., Albornoz, N. y Caro, M. (2018). Estandarización educativa en Chile: tensiones y consecuencias para el trabajo docente. Educacao unisinos (22)1, 83-90.

Bacigulpe, G. (16 de febrero de 2021). Toque de queda: Expertos contradicen al gobierno y llaman a evaluar su mantención. Diario Uchile. https://radio.uchile.cl/2021/02/16/toque-de-queda-expertos-contradicen-algobierno-y-llaman-a-evaluar-su-mantencion/

Badiou, A. (2020). Alain Badiou: ¿Qué cambios políticos provocará el coronavirus?. Televisa news. $\quad$ https://noticieros.televisa.com/especiales/alain-badiou-opinion-cambiospoliticos-coronavirus/

Cabezas, D., y Guerrero, S. (2021). Revuelta, asambleas territoriales y educación popular. En Elgueta, G., y Marchant, C. (Eds). De la Marcha y el Salto: Chile, octubre 2019. Editorial Tiempo Robado

Cárdenas, C., Guerrero, S., y Johnson, D (2021). Construir currículum desde abajo: avanzando en la documentación de una propuesta curricular en el contexto del COVID-19. Educación 30(58), 34-58.

Caro, M., y Reyes, L. (2020). Educación pública: trayectorias históricas y debates para la discusión de un nuevo orden constitucional en educación, Docencia 65, 6-32 http://revistadocencia.cl/web/images/ediciones/docencia 65.pdf

Caro, M. (2018a) Red de escuelas con sello experimental: hacia un proyecto de escuela pública para una vida digna, justa, democrática y socialmente protagónica. Docencia 63, 63-69.

Caro, M. (2018b). El conocimiento pedagógico-curricular que surge desde experiencias escolares transformativas, Docencia 61, 50-54. 
Caro, M., y Aguilar, M. (2018). Desarrollo del currículum en las aulas: perspectivas del profesorado. En Arratia, A., y Osandón, L. Políticas para el desarrollo del currículum: Reflexiones y propuestas. UNESCO-Santiago

Cienfuegos, R., Tironi, M., y Palma, K. (14 de mayo de 2020). Como gobernar un desastre: Diálogo, colaboración y democracia. Ciper Chile. https://www.ciperchile.cl/2020/05/14/como-gobernar-un-desastre-dialogocolaboracion-y-democracia/

Consejo Nacional de Educación (2020). Acuerdo $\mathrm{N}^{\circ}$ 080/2020. https://www.cned.cl/sites/default/files/acdo 080-2020 mineduc 0.pdf

Colectivo Chuang. (23 de Marzo de 2020). Contagio social: guerra de clases microbiológica en China. Revista de Frente. https://www.revistadefrente.cl/contagio-social-guerra-declases-microbiologica-en-china-del-colectivo-chuang/

Colegio de Profesoras y profesores de Chile (3 de julio de 2021). "Vuelta a clases en tiempos de pandemia": Encuesta del colegio de profesores arroja que $75,7 \%$ considera que no estan las condiciones para reabrir los establecimientos. Diario La Tercera. https://www.latercera.com/nacional/noticia/vuelta-a-clases-en-tiempos-depandemia-encuesta-de-colegio-de-profesores-arroja-que-757-considera-que-noestan-las-condiciones-para-reabrir-losestablecimientos/KQ4KKBKLOBAXXKTCXJIUPMDSLI/

Colegio de Profesoras y profesores de Chile (2020). Nuclearización: La propuesta del magisterio para abordar el currículum durante la pandemia. https://www.colegiodeprofesores.cl/2020/06/01/nuclearizacion-la-propuesta-delmagisterio-para-abordar-el-curriculum-durante-la-pandemia/

Colegio Médico de Chile A.G (26 de mayo de 2021). Gobierno responde a Colmed que Mesa Asesora Covid-19 no tiene funcionamiento formal e informa que no hay actas, $n i$ integrantes. https://www.colegiomedico.cl/gobierno-responde-a-colmed-que-mesaasesora-covid-19-no-tiene-funcionamiento-formal-e-informa-que-no-hay-actas-niintegrantes/

Cornejo, R. (2018). Políticas y reformas escolares: el experimento educativo chileno y su evolución. En Ruiz, C., Reyes, L., y Herrera, F. (Editores) Privatización de lo público en el sistema escolar. Chile y la agenda global de educación. LOM Editores.

Cornejo, R. y Reyes, L. (2008). La cuestión docente: Chile, experiencias organizacionales y acción colectiva de profesores. Foro latinoamericano de Políticas Educativas - FLAPE.

Cornejo, R., y González, E. (20 de abril de 2020b). El Mineduc y su postura frente a la pandemia: iuna mirada pública?. Radio Uchile. https://radio.uchile.cl/2020/04/20/el-mineduc-y-su-postura-frente-a-la-pandemiauna-mirada-publica/ 
Cornejo, R., y González, E. (25 de mayo de 2020a). ¿Desconocimiento o negociado? El fanatismo por el SIMCE. Radio Uchile. https://radio.uchile.cl/2020/05/25/desconocimiento-o-negociado-el-fanatismopor-el-simce/

Cortazar, J. (1996). La autopista del sur y otros cuentos. Penguin Books.

De Souza, B. (2020). La cruel pedagogía del virus. CLACSO

Díaz-Barriga, A. (2020). La escuela ausente, la necesidad de replantear su significado. En Casanova, H. (Coord.), Educación y pandemia: una visión académica (pp. 19-29). Universidad Nacional Autónoma de México, Instituto de Investigaciones sobre la Universidad y la Educación

Díaz, C. (22 de junio de 2021). Carlos Díaz: "El gobierno no ha dado garantías para que el retorno a las salas de clases sea seguro". Radio Uchile. https://radio.uchile.cl/2021/06/22/carlos-diaz-el-gobierno-no-ha-dado-garantiaspara-que-el-retorno-a-las-salas-de-clases-sea-seguro/

El Mostrador (25 de mayo de 2020) El talón de Aquiles en la gestión de la pandemia. Diario El mostrador.https://www.elmostrador.cl/noticias/pais/2020/05/25/el-talon-deaquiles-en-la-gestion-de-la-pandemia-cplt-advierte-falta-de-transparencia-en-datosde-fallecidos-y-hospitalizaciones-que-entrega-el-gobierno/

El Mostrador. (22 de julio de 2018). La insólita solución del ministro de Educación ante problemas en los colegios: “¿Por qué no hacen un bingo?”. Diario El Mostrador https://www.elmostrador.cl/noticias/pais/2018/07/22/la-insolita-solucion-delministro-de-educacion-ante-problemas-en-los-colegios-por-que-no-hacen-unbingo/

Equipos educativos de la Corporación Municipal de Renca. (2020). La educación pública en de Renca en tiempos de pandemia. https://www.renca.cl/wpcontent/uploads/2020/12/educacion-en-contexto-de-epidemia-renca2.pdf?_ga $=2.50772139 .327678920 .1627328674-1430121857.1627328674$

Figueroa, R. (25 de abril de 2021). Ministro de Educación: “Están todas las condiciones” para que colegios reanuden las clases presenciales". Diario La Tercera. https://www.latercera.com/nacional/noticia/ministro-de-educacion-estan-todaslas-condiciones-para-que-colegios-reanuden-las-clasespresenciales/H5DUJG6GFVDW5KBA5M04CU6PIQ/

Freire, P. (1970a). La Pedagogía del Oprimido de Paulo Freire. Siglo XXI

Freire, P. (1970b). Investigación y medotología de la investigación del Tema Generador. Reducción y codificación de temáticas. Instituto Agropecuario Colombiano. https://repository.agrosavia.co/handle/20.500.12324/1308?locale-attribute=en 
Foro por el Derecho a la Educación Pública. (19 de abril de 2020). Declaración de rechazo a las medidas del mineduc por pandemia Covid-19. http://derechoeducacionpublica.cl/declaracion-de-rechazo-a-las-medidas-delmineduc-por-pandemia-covid-19/

Foro por el Derecho a la Educación Pública. (Junio de 2019). La situación de la educación en Chile al 2019. $\quad$ http://derechoeducacionpublica.cl/wpcontent/uploads/2019/07/FODEP-2019-Informe-Luz-de-la-Situaci\%C3\%B3n-de-laEducaci\%C3\%B3n-en-Chile.pdf

Foro por el Derecho a la Educación (Comps). (2015). Una década de luchas y propuestas por el derecho a la educación. La palabra de los movimientos sociales. Santiago de Chile.

Gobierno de Chile (2021). Actualización al plan paso a paso: Nos cuidamos. https://s3.amazonaws.com/gobcl-prod/public files/Campa\%C3\%B1as/CoronaVirus/documentos/paso-a-paso/actualizacion Paso a Paso.pdf

Gentili, P. (2001). La exclusión y la escuela: el apartheid educativo como política de ocultamiento, Docencia 15, 4-11.

Gonzáles, J. (2015). Los principales problemas en el sistema educativo chileno neoliberal. En Foro por el Derecho a la Educación (Comps). (2015). Una década de luchas y propuestas por el derecho a la educación. La palabra de los movimientos sociales. Santiago de Chile.

Grundy, S. (1998). Producto o praxis del curriculum. Ediciones Morata.

Grez, S. y Foro por la Asamblea Consituyente (2015). Asamblea constituyente: la alternativa democrática para Chile. Editorial América en movimiento.

Gutierrez, C. (21 de abril de 2020). Gobierno y datos del Covid 19: Secretismo, manipulación y democracia. Ciper Chile. https://www.ciperchile.cl/2020/04/21/gobierno-y-datosdel-covid-19-secretismo-manipulacion-y-democracia/

Harvey, D. (2020). Políticas anticapitalistas en la era del covid 19. Revista del Frente. https://www.revistadefrente.cl/politicas-anticapitalistas-en-la-era-del-covid-19del-geografo-marxista-david-harvey/

Harvey, D. (2019). Construimos ciudades para que la gente invierta en vez de para que viva. La vanguardia. https://www.lavanguardia.com/cultura/20190819/464143674196/construimosciudades-para-que-la-gente-invierta-en-vez-de-para-que-viva.html

Harvey, D. (2007). Breve historia del neoliberalismo. Ediciones Akal, S.A.

Kridel, C. (2010). Encyclopedia of Curriculum Studies Encyclopedia of curriculum studies. SAGE Publications, Inc. https://doi.org/10.4135/9781412958806 
Lakoff, G. y Johnson, M. (1986). Metáforas de la vida diaria. Ediciones Cátedra.

Magendzo, A. (2008). Dilemas del currículum y la pedagogía: Analizando la reforma curricular desde una perspectiva crítica. LOM ediciones.

Ministerio de Educación (26 de febrero de 2021). Bases administrativas, técnicas y anexos para la licitación del concurso de proyectos de reinserción educativa y aulas de reingreso, año 2021. https://epja.mineduc.cl/reinsercion-escolar/fondoconcursable-proyectos-reinsercion-educativa-actualizado2021/

Ministerio de Educación (13 de octubre de 2020). Orientaciones para la vuelta a clases presenciales: Plan paso a paso. https://escolar.mineduc.cl/2020/10/13/orientaciones-para-la-vuelta-a-clasespresenciales-plan-paso-a-paso/

Ministerio de Salud (12 de mayo de 2020). Plan de acción coronavirus Covid-19: Reporte diario. $\quad$ https://cdn.digital.gob.cl/public files/Campa\%C3\%B1as/CoronaVirus/Reportes/12.05.2020 Reporte Covid19.pdf

Ministerio de Salud (20 de febrero de 2021). Resolución 143 exenta: Modifica resolución $\mathrm{N}^{\circ}$ 43 exenta, de 2021 https://www.bcn.cl/leychile/navegar?idNorma=1156146\&idVersion=2021-02-20

OCDE (2004). Revisión de Políticas Nacionales de Educación: Chile. https://www.oecdilibrary.org/education/revision-de-politicas-nacionales-de-educacionchile 9789264021020 -es

Osandón, L., y Pinto, R. (2018). El currículum nacional y la descentralización: políticas, institucionalidad y saberes. En Arratia, A., y Osandón, L. Políticas para el desarrollo del currículum. Reflexiones y propuestas. Ministerio de Educación-UNESCO Santiago. pp.155-184.

Paredes, F. (16 de febrero de 2021). Presidente de la Asociación Chilena de Municipalidades sobre retorno a clases: "Entendemos que las comunas que así lo estimen, podrán iniciar las clases de manera virtual. Eso está absolutamente claro". Tele 13 radio. https://www.tele13radio.cl/podcast/fm/presidente-de-la-asociacion-chilena-demunicipalidades-sobre-retorno-a

Pérez-Acle, T. (27 de marzo de 2020). Científico a cargo de la proyección de la epidemia en Chile: "El colapso de todo el sistema de salud es inevitable y se estima entre mayo y junio". El mostrador.

https://www.elmostrador.cl/destacado/2020/03/27/cientifico-a-cargo-de-laproyeccion-de-la-epidemia-en-chile-el-colapso-del-todo-el-sistema-de-salud-esinevitable-y-se-estima-entre-mayo-y-junio/

Pierola, G. (5 de mayo de 2020). Mesa social covid 19 le pide información al presidente de la república. Pauta. 
https://www.pauta.cl/politica/mesa-social-covid-19-le-pide-informacion-al-presidente-dela-republica

Pinto, R. (2005). Desafíos políticos actuales para el desarrollo de la educación social en nuestro país, Pensamiento Educativo, Revista de Investigación Latinoamericana 37(2), 117-141.

Plá, S. (2020). La pandemia en la escuela: entre la opresión y la esperanza. En Casanova, H. (Coord.), Educación y pandemia: una visión académica (pp. 30-38). Ciudad de México: Universidad Nacional Autónoma de México, Instituto de Investigaciones sobre la Universidad y la Educación

Puiggrós, A. (2020). Balance del estado de la educación, en época de pandemia en América Latina: el caso de Argentina. En Dussel, I., Ferrante, P., y Pulfer, D. Pensar la educación de pandemia: entre la emergencia, el compromiso y la espera (pp. 33-42). UNIPE, Editorial Universitaria.

Ramírez, F., y Comunicaciones CIAE (19 de mayo de 2016). Revolución pingüina: 2006-2016: Las transformaciones en la escena educacional chilena. Universidad de Chile. http://www.uchile.cl/noticias/121706/2006-2016-las-transformaciones-en-laescena-educacional-chilena

Observatorio Chileno de Políticas Educativas. (2020). Principales resultados de encuestas sobre el trabajo del profesorado chileno en periodo de pandemia. https://opech.cl/principales-resultados-de-encuestas-sobre-el-trabajo-delprofesorado-chileno-en-periodo-de-pandemia-condiciones-de-trabajo-y-malestar/

Ross, A. (2000). Curriculum Construction and Critique. Falmer Press.

Ruiz, C. (2010). De la república al mercado. Ideas educacionales y política en Chile. LOM Ediciones.

Saberes docentes (2020). Saberes que transforman la escuela, en tiempos de pandemia Cap.2 http://saberesdocentes.uchile.cl/videos/164067/saberes-que-transforman-laescuela-en-tiempos-de-pandemia-cap2

Salazar, G. (2020). Coyunturas constituyentes en Chile: oligarquías contra ciudadanos. Docencia 65 , 34-51. http://revistadocencia.cl/web/images/ediciones/docencia_65.pdf

Siches, I. (20 de marzo de 2020). Colmed asegura que información oficial sobre COVID-19 tiene inconsistencias, son incompletos y pide cierre urgente de Región Metropolitana. https://www.colegiomedico.cl/colmed-asegura-que-informacion-oficial-sobrecovid-19-tiene-inconsistencias-son-incompletos-y-pide-cierre-urgente-de-regionmetropolitana/ 
Sisto, V. (2020). La escuela abandonada a evaluaciones y estándares, confinada en el managerialismo. Praxis Educativa, 15, 1-26. https://doi.org/10.5212/PraxEduc.v.15.15777.107

Sobarzo, M. (2020). Covid 19 y los desafíos educativos del presente. Revista Enfoques Educacionales 17(2), 59-72.

UNESCO. (2021). Las respuestas educativas nacionales frente a la COVID-19. El panorama de América Latina y el Caribe. https://unesdoc.unesco.org/ark:/48223/pf0000377074

Vera, D. (26 de mayo de 2021). Gobierno responde al colmed que no hay actas o integrantes de mesa covid 19.

Biobio Chile. https://www.biobiochile.cl/noticias/nacional/chile/2021/05/26/es-informalgobierno-responde-al-colmed-que-no-hay-actas-o-integrantes-de-mesa-covid$\underline{19 . s h t m l}$ 